\title{
SIMULATION STUDY ON CONSTRUCTED RAPID INFILTRATION FOR TREATMENT OF SURFACE WASTEWATER IN TOWN
}

\author{
Zheng Yanxia ${ }^{1}$, Feng Shaoyuan ${ }^{2}$, Zhao Xuyang ${ }^{3, *}$ \\ ${ }^{1}$ Zheng Yanxia, Doctor. Resource \& Environment Department, Shijiazhuang College, Hebei, \\ 050035, P. R. China \\ ${ }^{2}$ Feng Shaoyuan, professor. College of Water Conservancy \& Civil Engineering, China \\ Agricultural University, Beijing, 100083, P. R. China \\ ${ }^{3}$ Zhao Xuyang, Professor. Resource \& Environment Department, Shijiazhuang College, \\ Hebei, 050035, P. R. China \\ * Corresponding author, Address: Shijiazhuang College, Shijiazhuang, 050035, Hebei, P. R. \\ China, Tel: 86-13931981959,Email: log2008@163.com
}

Abstract: $\quad$ On the base of land disposal, the objective of this study was to use constructed rapid infiltration (Abbreviation: CRI) to improve slightly polluted surface water in town. The data indicated that the average removal rates of $\mathrm{BOD}_{5}$ and $\mathrm{NH}_{4}{ }^{+}-\mathrm{N}$ were $80 \%$ and $65 \%$ in summer, respectively. In winter, the removal rates of $\mathrm{BOD}_{5}$ decreased evidently with the lowering of water temperature, but the change of $\mathrm{NH}_{4}{ }^{+}-\mathrm{N}$ was not obvious with the lowering of water temperature. The average removal rate of $\mathrm{NH}_{4}{ }^{+}-\mathrm{N}$ was $60 \%$ in winter. The study results indicated that the constructed rapid infiltration system had better purification effect on the slightly polluted water. The system could still operate normally at low temperature in winter.

Keywords: Constructed Rapid Infiltration; Water temperature; Surface wastewater

\section{INTRODUCTION}

As an ecological treating technique, the land treatment systems are of good developing prospects because of its advantages, such as simple of facilities, economization of investment, convenience of operation, lower cost

Yanxia, Z., Shaoyuan, F. and Xuyang, Z., 2008, in IFIP International Federation for Information Processing, Volume 259; Computer and Computing Technologies in Agriculture, Vol. 2; Daoliang Li; (Boston: Springer), pp. 851-858. 
of energy and better effect of purgation. But it does still have some problems. Among the problems, lower hydraulic loading and lower capability of treatment quantity per area were the most serious one. Constructed rapid infiltration was one kind of land treatment. It enhanced the hydraulic loading by replacing natural medium with artificial medium (Zhang et al., 2001, 2002; He 2001, 2005; Zheng, 2005). Buried sand-filter system and CRI system shared many similarities, such as filter velocity and the removal of particles, microorganisms, and biodegradable substances, but the hydraulic loading was slow, typically 0.2 meters per day $(\mathrm{m} / \mathrm{d})($ Pauel et al., 1990; Markus et al., 1993; Andreas, 1997; Zhang et al., 2001). Some information about buried sand-filter may be helpful. In china, CRI system was developed in recent years, it was necessary to research more.

CRI system was utilized to improve the slightly polluted surface water; especially the application in the northern low-temperature area was studied rarely. For the feasibility of exploring CRI system to improve slightly polluted surface water, this paper developed Simulation experimental study on CRI system for $\mathrm{BOD}_{5}$ and $\mathrm{NH}_{4}{ }^{+} \mathrm{N}$ removal effect under different seasons.

\section{MATERIALS AND METHODS}

\subsection{Experimental apparatus}

The experimental apparatus had been constructed and operated by the canal under the reservoir. Two replicates were performed per sand. Figure 1 is the sketch of the experimental apparatus of CRI system.

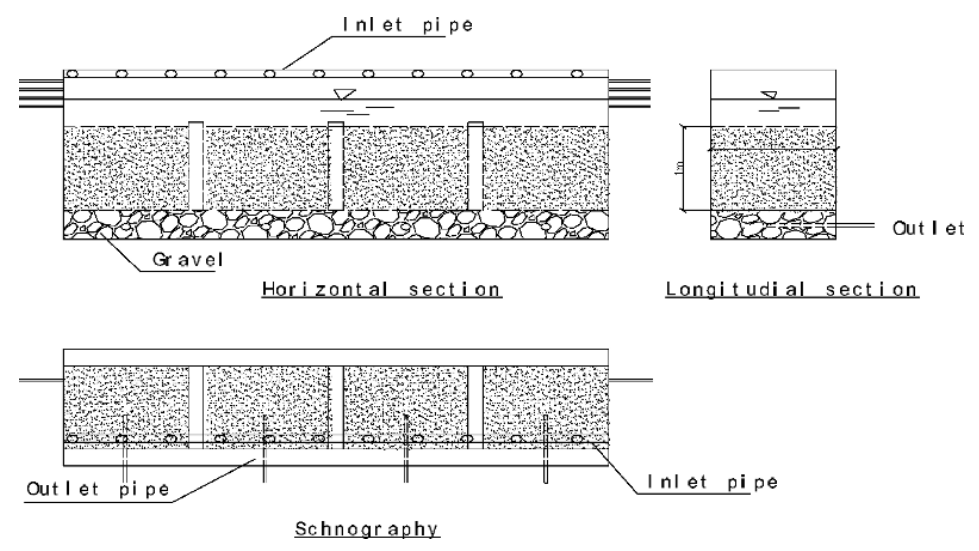

Figure 1. The sketch of experimental CRI system 


\subsection{Porous media}

Sand was used as porous media in the study. Mechanical composition of the two kinds of sand was described in Table 1. Two kinds of sand were not different obviously, were taken from the potential effluent recharge site in a river way.

Table 1. Mechanical composition of porous media

\begin{tabular}{|c|c|c|c|c|c|c|c|}
\hline \multicolumn{5}{|c|}{ Size/mm } & \multirow{2}{*}{$p H$} & \multirow{2}{*}{$\begin{array}{l}\text { Organic } \\
\text { matter/\% }\end{array}$} & \multirow{2}{*}{$\begin{array}{c}\mathrm{CEC} / \\
(\mathrm{cmol} / \mathrm{kg})\end{array}$} \\
\hline $10-2$ & $2-0.5$ & $0.5-0.25$ & $0.25-0.075$ & $<0.075$ & & & \\
\hline $5.26 \%$ & $41.65 \%$ & $39.91 \%$ & $10.66 \%$ & $2.73 \%$ & 7.95 & 0.45 & 2.33 \\
\hline $0 \%$ & $47.26 \%$ & $41.33 \%$ & $9.61 \%$ & $1.8 \%$ & 7.8 & 0.52 & 2.2 \\
\hline
\end{tabular}

\subsection{Analytic methods of water quality}

Influent water in this study was taken from surface wastewater in town. Parameters were determined by Environmental quality standard for surface water (State Environmental Protection Administration of China, GB 3838 2002).

\section{RESULTS AND DISCUSSION}

\subsection{Water temperature on removal efficiency of $\mathrm{BOD}_{5}$}

Figure 2 showed effect of water temperature on removal of $\mathrm{BOD}_{5}$. Removal of $\mathrm{BOD}_{5}$ lowered with the decrease of water temperatures. The average removal rate of $\mathrm{BOD}_{5}$ was $80 \%$ in summer with high temperature; in autumn with middle temperature and in winter with low temperature, the average removal rate of $\mathrm{BOD}_{5}$ was $30 \%$. Water temperature and removal rate of $\mathrm{BOD}_{5}$ had similar trend of variation with a correlation coefficient of 0.9199 .

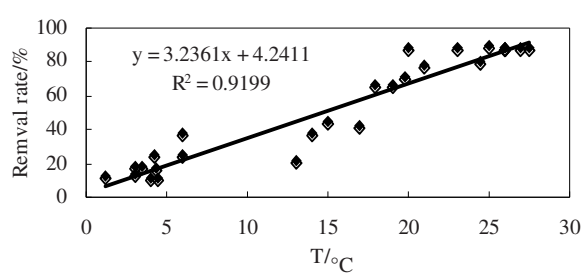

Figure 2. Effect of water temperature on removal of $\mathrm{BOD}_{5}$ 
Basis on reaction formula equation, CRI system can be assumed as a plug flow reactor. That is, only in CRI system direction perpendicular to the flow phenomena was mixed, and the flow direction was not mixed. Of course, this was an idealized model, but from a theoretical point of view, the analysis was feasible (Long, 2002). Figure 3 was Plug Flow Reactor Model.

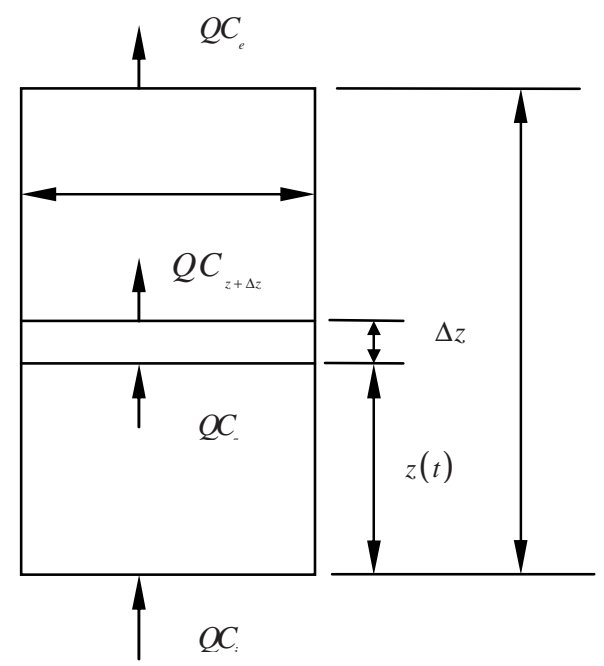

Figure 3. The sketch of Plug Flow Reactor Model

Calculated for energy conservation in $A \Delta z$ :

$$
Q C_{z}+(A \Delta z) r=Q C_{z+\Delta z}+(A \Delta z)\left(d C_{z} / d t\right)
$$

Where: $Q$ is flow. $C_{z}$ is concentration. $r$ is reaction rate

Ordered $\Delta z \rightarrow d z$, Equation (1)can be written:

$$
-(Q / A)\left(d C_{z} / d z\right)+r=d C_{z} / d t
$$

Where $Q / A$ can be used to replace by $U$, and $z / U$ can be used to replace by $\theta$, omitted subscript $z$, equation (2) can be written:

$-(d C / d \theta)+r=d C / d t$

In steady state, $d C / d t=0$ :

$$
d C / d \theta=r
$$

Due to the low concentration, the removal rate followed the first-order reaction formula:

$$
r=-k C
$$

Where: $k$ is reaction rate constant. 
Put equation (5) into equation (4), and integration

$$
C=C_{i} \exp (-k \theta)
$$

On both sides of equation (6) with log:

$$
\ln \left(C_{i} / C\right)=k \theta
$$

Basis on the concentration of $\mathrm{BOD}_{5}$, the approximation of reaction rate $k$ can be drawn in CRI system. $k$ was a coefficient with water temperature. Such as $\mathrm{BOD}_{5}, K_{20^{\circ} \mathrm{C}} / K_{25^{\circ} \mathrm{C}}$ was 0.94 , and $K_{10^{\circ} \mathrm{C}} / K_{15^{\circ} \mathrm{C}}$ was 0.48 , and $K_{15^{\circ} \mathrm{C}} / K_{20^{\circ} \mathrm{C}}$ was 0.93 . These indicated reaction rate decreased $6 \%$, when water temperature was dropped from $25^{\circ} \mathrm{C}$ to $20^{\circ} \mathrm{C}$; Reaction rate decreased $7 \%$, when water temperature decreased from $20^{\circ} \mathrm{C}$ to $15^{\circ} \mathrm{C}$; reaction rate decreased $52 \%$, when water temperature decreased from $15^{\circ} \mathrm{C}$ to $10^{\circ} \mathrm{C}$. These suggested water temperature more low; reaction rate decreased the proportion more big. This accorded with the experimentation result that the effect of change of water temperature was little in high temperature stage, but in low temperature stage, the effect was obvious.

\subsection{Water temperature on removal efficiency of $\mathrm{NH}_{4}{ }^{+}-\mathrm{N}$}

Figure 4 showed effect of water temperature on removal of $\mathrm{NH}_{4}^{+}{ }^{-} \mathrm{N}$. Removal of $\mathrm{NH}_{4}{ }^{+} \mathrm{N}$ was not obvious with the change of water temperature. But the trend was increased with the increasing of water temperature. Firstly, $\mathrm{NH}_{4}{ }^{+} \mathrm{N}$ was adsorbed into the infiltration media and happened nitration. Because $\mathrm{NH}_{4}{ }^{+} \mathrm{N}$ was biochemical substances, it was totally absorbed by microorganism. So the removal rates of $\mathrm{NH}_{4}{ }^{+}-\mathrm{N}$ were more constant than on the removal of organic matter. Even in the low temperature close to $0^{\circ} \mathrm{C}$, the ammonia removal rate remained at $45 \%$. Therefore, CRI system had a certain removal effect on $\mathrm{NH}_{4}{ }^{+}-\mathrm{N}$ in slightly polluted water under low temperatures.

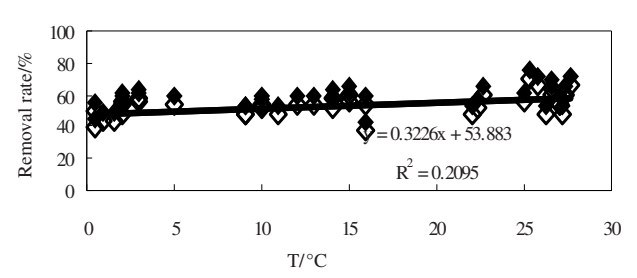

Figure 4. Effect of water temperature on removal of $\mathrm{NH}_{4}{ }^{+}-\mathrm{N}$ 
Basis on reaction formula equation, the lower of $\mathrm{NH}_{4}-\mathrm{N}$ removal rate indicated the lower of $\mathrm{NH}_{4}{ }^{+} \mathrm{N}$ removal speed in CRI sỳstem. Therefore, Monod kinetic equation was used to note ammonia oxidation reaction (Gu, 1993).

Basis on Monod equation:

$$
\mu_{N S}=\left(\mu_{\max }\right)_{N S} N /\left(K_{N}+N\right)
$$

Where: $\mu_{N S}$ is growth rate of nitrosobacteria $\left(\min ^{-1}\right) .\left(\mu_{\max }\right)_{N S}$ is max growth rate of nitrosobacteria $\left(\mathrm{min}^{-1}\right) . N$ is concentration of $\mathrm{NH}_{4}{ }^{+}-\mathrm{N}(\mathrm{mg} / \mathrm{L})$. $K_{N}$ is saturation constant $\left(\mathrm{mg} / \mathrm{L}, K_{N}=10^{0.051 T-1.158}\right) . T$ is temperature $\left({ }^{\circ} \mathrm{C}\right)$.

$$
\begin{aligned}
& (d X / d t) / X=-y_{0}(d N / d t) / X \\
& \mu_{N S}=(d X / d t) / X \\
& \nu=-(d N / d t) / X \\
& \therefore \mu_{N S}=y_{0} v \text { 或 }\left(\mu_{\max }\right)_{N S}=y_{0} v_{\max }
\end{aligned}
$$

Where: $X$ is concentration of nitrosobacteria $(\mathrm{mg} / \mathrm{L}) . y_{0}$ is yield (mg Nitrosobacteria/mg $\left.\mathrm{NH}_{4}{ }^{+}-\mathrm{N}\right) . v$ is removal speed of $\mathrm{NH}_{4}{ }^{+}-\mathrm{N}\left(\mathrm{min}^{-1}\right)$. $v_{\text {max }}$ is max removal speed of $\mathrm{NH}_{4}{ }^{+}-\mathrm{N}\left(\min ^{-1}\right)$.

Put equation (12) into equation(10):

$$
v=v_{\max } N /\left(K_{N}+N\right)
$$

In the wastewater treatment process, removal of the pollutants was major, and microbial growth was the result of pollutants removal. Therefore, equation (13) was more practical.

Assumed:

(1) The nitrosobacteria concentration of entrance was similar to the concentration of exports in CRI system. At this point, the nitrosobacteria concentration can be said that the average concentration $X_{a}$.

(2) The using speed of $\mathrm{NH}_{4}{ }^{+}-\mathrm{N}$ was same to the reducing speed of $\mathrm{NH}_{4}{ }^{+}-\mathrm{N}$ concentration along the water flow direction.

So:

$$
v=-(d N / d t) / X_{a}=v_{\max } N /\left(K_{N}+N\right)
$$

Arranged: 


$$
K_{N} d N+N d N=-v_{\max } X_{a} N d t
$$

Integral:

$$
\left(N_{i}-N_{e}\right)+K_{N} \ln \left(N_{i} / N_{e}\right)=v_{\max } X_{a} t
$$

Ordered $V_{\max }=v_{\max } X_{a}$, called the $\max$ removal rate $(\mathrm{mg} / \mathrm{L} \bullet \mathrm{min})$ :

$$
\left(N_{i}-N_{e}\right)+K_{N} \ln \left(N_{i} / N_{e}\right)=V_{\max } t
$$

Where: $N_{i}$ is concentration of $\mathrm{NH}_{4}{ }^{+}-\mathrm{N}$ of entrance $(\mathrm{mg} / \mathrm{L}) . N_{e}$ is concentration of $\mathrm{NH}_{4}{ }^{+}-\mathrm{N}$ of exports (mg/L).

Basis on the concentration of $\mathrm{NH}_{4}{ }^{+} \mathrm{N}$, the approximation of max removal speed $V_{\max }$ can be drawn in CRI system. $V_{\max }$ was a coefficient with water temperature. Such as $\mathrm{NH}_{4}{ }^{+} \mathrm{N}, \quad V_{\max \left(5^{\circ} \mathrm{C}\right)} / V_{\max \left(10^{\circ} \mathrm{C}\right)}$ was 0.65 , and $V_{\max \left(0.5^{\circ} \mathrm{C}\right)} / V_{\max \left(5^{\circ} \mathrm{C}\right)}$ was 0.525 . This indicated max removal speed decreased $35 \%$, when water temperature was dropped from $10^{\circ} \mathrm{C}$ to $5^{\circ} \mathrm{C}$; The max removal speed decreased $47.5 \%$, when water temperature decreased from $5^{\circ} \mathrm{C}$ to $0.5^{\circ} \mathrm{C}$. Removal efficiency of $\mathrm{NH}_{4}{ }^{+} \mathrm{N}$ was not significantly different with the increase of water temperatures. The average removal rate of $\mathrm{NH}_{4}{ }^{+}-$ $\mathrm{N}$ was $65 \%$ in summer with high temperature, in autumn with middle temperature and in winter with low temperature. The changes of $\mathrm{NH}_{4}{ }^{+}-\mathrm{N}$ were not obvious with the lowering of water temperature.

CRI system had better removal effect on $\mathrm{NH}_{4}{ }^{+}-\mathrm{N}$ in slightly polluted water, but water temperature had not obvious effect on removal effect. This suggested that nitrobacteria and nitrosomonas adapted to low temperature (Wang et al., 1999; Zhou et al., 2000). Therefore, CRI system had a certain removal effect on $\mathrm{NH}_{4}{ }^{+}-\mathrm{N}$ in slightly polluted water under low temperatures.

\section{CONCLUSIONS}

(1) CRI system had a significant removal effect on slightly polluted surface water. The simulation experiment indicated that the average removal rates of $\mathrm{BOD}_{5}$ and $\mathrm{NH}_{4}{ }^{+}-\mathrm{N}$ were $80 \%$ and $65 \%$ in summer with high temperature, respectively. The average removal rates of $\mathrm{BOD}_{5}$ and $\mathrm{NH}_{4}{ }^{+}-\mathrm{N}$ were $30 \%$ and $60 \%$ in winter with low temperature, respectively.

(2) Removal of $\mathrm{BOD}_{5}$ was lowered with the lowering of water temperature. In winter, the removal rates of $\mathrm{BOD}_{5}$ lowered evidently with 
the lowering of water temperature, but the change of $\mathrm{NH}_{4}{ }^{+}-\mathrm{N}$ was not obvious with the lowering of water temperature.

(3) The removal efficiency decreased with the lowering of water temperature. This suggested that microbial activity decreased with the lowering of water temperature. The lower water temperature, microbial activity was affected greater. In winter, the CRI system should take measures to keep from freeze. The system could operate normally at low temperature in winter.

\section{REFERENCES}

Andreas S. \& Markus B. Transport phenomena in intermittent filters [J]. Wat. Sci. Tech., 1997, 35(6): 13-20.

$\mathrm{Gu}$ X.S. Wastewater mathematical models of biological treatment $[\mathrm{M}]$. Tsinghua University Press, 1993. (In Chinese)

He J.T. A new technique for wastewater reuse: Constructed rapid infiltration system (picture) [J]. Earth Science Frontiers (China University of Geosciences, Beijing; Peking University), 2005, 12 (Suppl.): 12-13. (In Chinese)

He J.T. Experimental study on constructed rapid infiltration system [D]. Beijing: China University of Geosciences, Beijing, 2001. (In Chinese)

Long X.Q. Bioactive filter characteristics and transformation projects [D]. Tsinghua University, 2001. (In Chinese)

Markus B. \& Schwager A. Dynamic behavior of intermittent buried filters [J]. Wat. Sci. Tech., 1993, 28(10): 99-107.

Pauel S. \& Markus B. Onsite wastewater treatment with intermittent buried filters [J]. Wat. Sci. Tech., 1990, 22(3/4): 93-100.

Wang Z.S. \& Liu W.J. Drinking Water Treatment Processes with Micro-polluted Raw Water [M]. Beijing: China Architecture and Building Press, 1999. (In Chinese)

Zhang J.B. Study on constructed rapid infiltration system for wastewater treatment [D]. Beijing: China University of Geosciences, Beijing, 2002. (In Chinese)

Zhang J.B., Chen H.H. \& Zhong Z.X. Buried sand-filter system and its environmental significance [J]. Geoscience, 2001, 15(3): 346-350. (In Chinese)

Zhang J.B., Chen H.H.\& Zhong Z.X. The experimental study on the treatment of both wastewater by artificial rapid infiltration composite system [J]. Hydrogeology and Engineering Geology, 2001, 28(6): 30-32. (In Chinese)

Zheng Y.X., Feng S.Y.\& Cai J.B. Experimental study on removal of organic substance in reservoir water by means of soil aquifer treatment system [J]. Journal of Hydraulic Engineering, 2005, 36(9): 29-32. (In Chinese)

Zhou Q.Y.\& Gao T.Y. Microbiology of Environmental Engineering [M]. Beijing: Higher Education Press, 2000. (In Chinese) 